\title{
PENGENDALIAN PEMAKAIAN BAHAN BAKAR GAS PT INDONESIA POWER UPJP PRIOK MENGGUNAKAN PETA KENDALI ARMAST
}

\author{
MIFTAHUL JANNAH HB, HAZMIRA YOZZA, FERRA YANUAR \\ Jurusan Matematika, \\ Fakultas Matematika dan Ilmu Pemgetahuan Alam, Universitas Andalas \\ Kampus UNAND Limau Manis Padang, Indonesia. \\ email : miftahuljnhb@gmail.com, izzatirahmihg@sci.unand.ac.id,ferrayanuar@sci.unand.ac.id
}

\begin{abstract}
Abstrak. PT Indonesia Power UPJP Priok merupakan salah satu anak perusahaan PT PLN (Persero) yang bergerak pada sektor pembangkitan listrik. PT Indonesia Power UPJP Priok menggunakan bahan bakar gas Neraca Regas (NR) dan Perusahaan Gas Negara (PGN) untuk menjalankan generator yang akan menghasilkan listrik. Dalam proses pembangkitan dilakukan monitoring dan perencanaan terhadap pemakaian bahan bakar gas, agar menghasilkan energi listrik sesuai yang ditargetkan oleh perusahaan. Oleh karena itu perlu dilakukannya pengendalian terhadap pemakaian gas dengan menggunakan peta kendali. Pada penelitian ini menggunakan peta kendali ARMAST karena proses pemakaian gas di PT Indonesia Power UPJP Priok berlangsung setiap hari, sehingga data pemakaian bahan bakar gas termasuk jenis data runtun waktu. Hasil penelitian menunjukkan bahwa proses pemakaian bahan bakar gas PGN belum terkendali secara statistik, karena terdapat data yang berada diluar batas kendali.
\end{abstract}

Kata Kunci: Data Runtun Waktu, Pengendalian, Peta Kendali ARMAST

\section{Pendahuluan}

Listrik merupakan salah satu kebutuhan dasar bagi masyarakat saat ini. PT PLN (Persero) sebagai penyedia energi listrik harus mencukupi kebutuhan listrik masyarakat. Dalam penyediaannya, PT PLN (Persero) memiliki sektor pembangkit listrik sebagai sumber terbentuknya energi listrik salah satunya PT Indonesia Power UPJP Priok. PT Indonesia Power UPJP Priok menggunakan bahan bakar utama gas Neraca Regas (NR) dan Perusahaan Gas Negara (PGN) untuk menjalankan generator yang akan menghasilkan energi listrik. Pada saat proses pembangkitan dilakukan monitoring dan perencaanan untuk memperhatikan jumlah pemakaian gas agar pemakaian berada pada level tertentu. Oleh karena itu diperlukan upaya untuk menjamin pemakaian gas dengan melakukan pengendalian kualitas.

*penulis korespondensi 
Pengendalian kualitas statistik yang bisa digunakan yaitu peta kendali. Penggunaan peta kendali tergantung pada jenis data yang akan dikendalikan. Data pemakaian gas merupakan jenis data runtun waktu karena proses pemakaian gas di PT Indonesia Power UPJP Priok berlangsung setiap hari. Beberapa peneliti telah menerapkan penggunaan peta kendali diantaranya yaitu Istikhomah [1] yang membahas pengendalian kualitas karet menggunakan peta kendali P. Nelwati [4] meneliti penggunaan peta kendali Exponentially Moving Average (EWMA) pada data runtun waktu yaitu jumlah wisatawan yang berkunjung ke Sumatera Barat. Peta kendali lainnya untuk data runtun waktu yaitu Peta Kendali ARMAST. Dengan demikian penelitian ini bertujuan mengkonstruksi peta kendall ARMAST pada data pemakaian gas di PT Indonesia Power UPJP Priok.

\section{Landasan Teori}

\subsection{Pengendalian Kualitas Statistik dengan Peta Kendali}

Kualitas merupakan keseluruhan karakteristik produk atau jasa yang mampu memenuhi dan memuaskan kebutuhan konsumen[2]. Karakteristik tersebut yang akan menjadi pertimbangan bagi konsumen dalam menilai kualitas dari produk atau jasa, setiap perusahaan harus menyadari kebutuhan dalam peningkatan kualitas. Oleh karena itu, diperlukan pengendalian kualitas untuk memonitoring dan perencanaan terhadap produk dan proses dengan menggunakan metode statistik. Salah satu alat pengendalian kualitas statistik yaitu peta kendali.

Peta kendali digunakan untuk mendeteksi apakah suatu proses berada dalam batas pengendalian atau tidak, peta kendali tersebut berupa grafik pada diagram kartesius yang dilengkapi dengan tiga garis yaitu : garis pusat (center line) sebagai nilai tengah karakteristik kualitas dan dua garis lainnya sebagai batas kendali atas (upper control limit) dan batas kendali bawah (lower control limit).

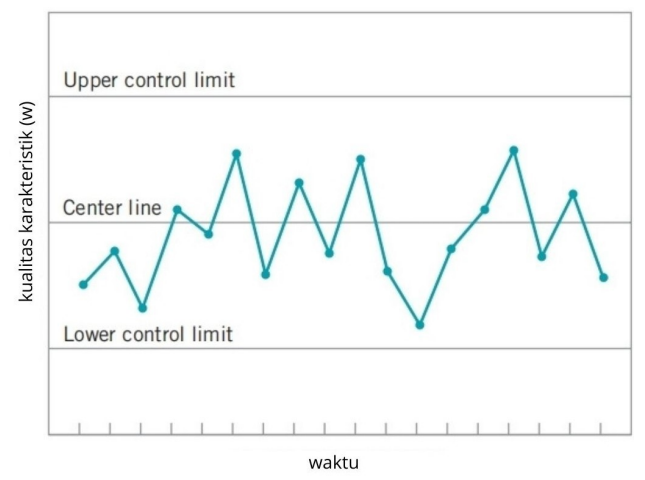

Gambar 1: Ilustrasi peta kendali

Gambaran umum dari peta kendali dapat dilihat pada Gambar 1. Misalkan w merupakan karakteristik kualitas yang menjadi perhatian dengan nilai tengah dari $w$ adalah $\mu_{w}$ dan standar deviasi dari $w$ adalah $\sigma_{w}$, maka persamaan UCL, CL dan 
LCL dituliskan sebagai berikut [2].

$$
\begin{aligned}
U C L & =\mu_{w}+L \sigma_{w}, \\
C L & =\mu_{w}, \\
L C L & =\mu_{w}-L \sigma_{w},
\end{aligned}
$$

dimana $L$ adalah jarak batas kendali dari garis tengah, umumnya bernilai 1,2 , dan 3 , semakin besar nilai $L$ menunjukkan semakin lebar batas suatu peta kendali.

\subsection{Analisis Data Runtun Waktu}

Data runtun waktu adalah serangkaian data yang dikumpulkan dari waktu ke waktu secara berurutan dengan periode waktu berupa tahunan, bulanan, atau bahkan jam atau hari dalam beberapa kasus.

\subsubsection{Kestasioneran}

Data runtun waktu dikatakan stasioner jika nilai tengah dan variansnya kostan dari waktu kewaktu, maka $E\left(Z_{t}\right)=\mu_{t}=\mu, \operatorname{Var}\left(Z_{t}\right)=E\left(Z_{t}-\mu_{Z}\right)^{2}=\sigma^{2}$ dimana $\mu$ dan $\sigma^{2}$ bebas terhadap $t[5]$. Jika data tidak stasioner terhadap nilai tengah maka dilakukan pembedaan (differencing) dengan menggunakan operator shift mundur (backward shift) yaitu $B Z_{t}=Z_{t-1}$ [3]. Secara umum untuk pembedaan orde $d$ adalah $\nabla^{d} Z_{t}=(1-B)^{d} Z_{t}$. Jika data tidak stasioner terhadap ragam maka dilakukan transformasi Box-Cox dengan menggunakan persamaan [3]

$$
T\left(Z_{t}\right)=\left\{\begin{array}{ll}
\frac{Z_{t}^{\lambda}-1}{\lambda} & \lambda \neq 0 \\
\ln Z_{t} & \lambda=0
\end{array},\right.
$$

Pemeriksaan kestasioneran dapat dilakukan dengan menggunakan Uji Augmented Dickey Fuller (ADF). Hipotesis yang diuji adalah :

$H_{0}: \delta=0$ (data tidak stasioner)

$H_{1}: \delta \neq 0$ (data stasioner)

Pengujian dilakukan dengan statistik uji

$$
t=\frac{\hat{\delta}}{S E(\hat{\delta})}
$$

Diambil keputusan tolak $H_{0}$ dengan taraf nyata $\alpha=0.05$ jika $\left|t_{\text {hitung }}\right| \geq t_{\frac{\alpha}{2}, n-1}$ yang berarti data stasioner.

\subsubsection{Autokorelasi}

Autokorelasi adalah korelasi yang terjadi pada data yang sama antar waktu. Autokorelasi ini sering terjadi pada data runtun waktu.

(1) Fungsi Autokorelasi merupakan suatu fungsi yang menunjukkan adanya hubungan atau korelasi pada data yang sama antar waktu. Persamaan autokorelasi antara $Z_{t}$ dan $Z_{t+k}$ sebagai [5] 


$$
\rho_{k}=\frac{\operatorname{Cov}\left(Z_{t}, Z_{t+k}\right)}{\sqrt{\operatorname{Var}\left(Z_{t}\right)} \sqrt{\operatorname{Var}\left(Z_{t+k}\right)}}=\frac{\gamma_{k}}{\gamma_{0}}
$$

dengan $\operatorname{Cov}\left(Z_{t}, Z_{t+k}\right)=E\left[\left(Z_{t}-\mu_{t}\right)\left(Z_{t+k}-\mu_{t+k}\right)\right]=\gamma_{(|t-(t+k)|)}$

(2) Fungsi Autokorelasi Parsial digunakan untuk mengukur tingkat keeratan antara $Z_{t}$ dan $Z_{t+k}$, apabila pengaruh dari time lag $1,2,3, \cdots, k-1$ dianggap terpisah. Nilai fungsi autokorelasi parsial pada lag- $k$ adalah [5]

$$
\phi_{k k}=\frac{\rho_{k}-\sum_{j=1}^{k-1} \phi_{k-1, j} \rho_{k-j}}{1-\sum_{j=1}^{k-1} \phi_{k-1, j} \rho_{j}},
$$

\subsubsection{Proses White Noise}

Suatu proses $\left\{a_{t}\right\}$ disebut proses white noise jika proses tersebut terdiri dari peubah acak yang berurutan tidak saling berkorelasi dengan $E\left(a_{t}\right)=\mu_{a}=0, \operatorname{Var}\left(a_{t}\right)=\sigma^{2}$ dan $\gamma_{k}=\operatorname{Cov}\left(a_{t}, a_{t+k}\right)=0$ untuk $k \neq 0[5]$.

Proses white noise dapat ditunjukkan dengan menggunakan Uji Ljung-Box. Hipotesis yang digunakan adalah :

$H_{0}: \rho_{1}=\rho_{2}=\cdots=0$ (tidak terdapat korelasi pada residual)

$H_{1}$ :minimal terdapat satu $\rho_{k} \neq 0$ untuk $k=1,2, \cdots, K$ (terdapat korelasi pada residual)

Pengujian dilakukan dengan statistik uji [3]

$$
Q_{K}=n(n+2) \sum_{k=1}^{K} \frac{\rho_{k}^{2}}{n-k}
$$

Diambil keputusan tolak $H_{0}$ dengan taraf nyata $\alpha=0.05$ jika nilai $Q \geq X_{\alpha, k-p-q}^{2}$ atau $p$-value $<\alpha$ yang berarti terdapat korelasi antar residual.

\subsubsection{Model Data Runtun Waktu}

\section{Model Autoregressive (AR)}

Model Autoregressive (AR) adalah model stasioner dari data runtun waktu dimana nilai pengamatan waktu ke- $t$ dipengaruhi oleh nilai pengamatan sebelumnya. Bentuk umum model AR dinyatakan sebagai [5]

$$
Z_{t}=\phi_{1} Z_{t-1}+\phi_{2} Z_{t-2}+\cdots+\phi_{p} Z_{t-p}+a_{t}
$$

\section{Model Moving Average (MA)}

Model Moving Average (MA) adalah model yang menunjukkan pengamatan pada waktu $t$. Bentuk umum model MA dinyatakan sebagai berikut [5]

$$
Z_{t}=a_{t}-\theta_{1} a_{t-1}-\theta_{2} a_{t-2}-\cdots-\theta_{q} a_{t-q} .
$$




\section{Autoregressive Moving Average (ARMA)}

Model ARMA merupakan campuran dari $\operatorname{AR}(p)$ dan $\operatorname{MA}(q)$. Bentuk umum model ARMA dinyatakan sebagai [5]

$$
Z_{t}=\phi_{1} Z_{t-1}+\phi_{2} Z_{t-2}+\cdots+\phi_{p} Z_{t-p}+a_{t}-\theta_{1} a_{t-1}-\theta_{2} a_{t-2}-\cdots-\theta_{q} a_{t-q} .
$$

\section{Model ARIMA}

Model ARIMA merupakan modifikasi dari model ARMA dengan penambahan parameter $d$ yang merupakan jumlah proses differencing(pembedaan). Bentuk umum model ARIMA dapat ditulis sebagai berikut [5]

$$
\phi(B)(1-B)^{d} Z_{t}=\theta(B) a_{t},
$$

dimana $(1-B)^{d} Z_{t}$ merupakan data runtun waktu yang stasioner pada pembedaan ke- $d$.

\subsection{Identifikasi Model}

Identifikasi model menggunakan plot ACF dan plot PACF. Plot ACF adalah plot yang digunakan untuk menentukan nilai orde $q$ pada MA dan Plot PACF adalah plot yang digunakan untuk menentukan orde $p$ pada AR.

Tabel 1: Identifikasi Model dengan ACF dan PACF

\begin{tabular}{|c|c|c|}
\hline Model & ACF & PACF \\
\hline $\operatorname{AR}(p)$ & Menurun secara cepat & Terpotong setelah lag ke- $p$ \\
MA $(q)$ & Terpotong setelah lag ke- $q$ & Menurun secara cepat \\
ARMA $(p, q)$ & Menurun secara cepat & Menurun secara cepat \\
\hline
\end{tabular}

\subsection{Estimasi dan Pengujian Signifikan Parameter}

Setelah dilakukan identifikasi model, menentukan nilai estimasi parameter dan dilakukan pengujian signifikan parameter.

Pengujian parameter $\theta_{i}$ pada model ARMA, dengan hipotesis yang digunakan adalah $[3]$

$H_{0}: \theta_{i}=0$ untuk $i=1, \cdots, q$ (parameter tidak signifikan)

$H_{1}: \theta_{i} \neq 0$ untuk $i=1, \cdots, q$ (parameter signifikan)

Pengujian dilakukan dengan statistik uji sebagai berikut:

$$
t=\frac{\hat{\theta}_{i}}{S E\left(\hat{\theta}_{i}\right)}
$$

Diambil keputusan tolak $H_{0}$ dengan taraf nyata $\alpha=0.05$ jika nilai $\left|t_{\text {hitung }}\right|>$ $t_{\frac{\alpha}{2}, n-n_{p}}$ atau $p$-value $<\alpha$.

Pengujian parameter $\phi_{j}$ pada model ARMA, dengan hipotesis yang digunakan adalah[3] 
$H_{0}: \phi_{j}=0$ untuk $j=1, \cdots, p$ (parameter tidak signifikan)

$H_{1}: \phi_{j} \neq 0$ untuk $j=1, \cdots, p$ (parameter signifikan)

Pengujian dilakukan dengan statistik uji sebagai berikut:

$$
t=\frac{\hat{\phi}_{j}}{S E\left(\hat{\phi}_{j}\right)}
$$

Diambil keputusan tolak $H_{0}$ dengan taraf nyata $\alpha=0.05$ jika nilai $\left|t_{\text {hitung }}\right|>$ $t_{\frac{\alpha}{2}, n-n_{p}}$ atau $p$-value $<\alpha$.

\subsection{Pemilihan Model Terbaik}

Pemilihan model terbaik dapat dilakukan dengan membandingkan nilai Akaikes Information Criterion (AIC). Persamaan AIC adalah sebagai berikut[5]

$$
A I C=\log \hat{\sigma}+\frac{n+2 k}{n}
$$

\section{Metode Penelitian}

Data yang digunakan dalam penelitian ini merupakan data sekunder yang diperoleh dari Bidang Niaga PT Indonesia Power UPJP Priok pada bulan Januari - Agustus 2020 sebanyak 182 data. Variabel yang terlibat adalah data pemakaian bahan bakar gas PGN di PT Indonesia Power yang diperoleh dari PT PGN.

Tahapan yang dilakukan untuk membentuk peta kendali ARMAST.

(1) Membahas kembali pembentukan peta kendali ARMAST

(2) Membentuk peta kendali ARMAST untuk pemakaian gas PGN di PT Indonesia Power dengan langkah-langkah berikut.

a. Menentukan model runtun waktu data pemakaian gas PGN di PT Indonesia Power dengan langkah-langkah berikut.

1. Pemeriksaan kestasioneran data

2. Mengidentifikasi model data runtun waktu

3. Mengestimasi dan menguji signifikansi parameter.

4. Pemeriksaan white noise

5. Menentukan model terbaik

b. Menentukan peta kendali ARMAST dengan langkah-langkah

1. Menghitung nilai mean dan variansi residual dari data.

2. Menghitung UCL, CL, LCL, dan menggambarkan peta kendali.

3. Plot data pada peta kendali

(3) Interpretasi peta kendali yang dihasilkan.

\section{Pembahasan}

\subsection{Peta Kendali ARMAST}

Peta kendali ARMAST merupakan salah satu peta kendali yang digunakan untuk data runtun waktu stasioner yang dibuat berdasarkan pemantauan model ARMA 
dari proses model ARMA pada data [6].

Bentuk pemantauan model Autoregressive Moving Average (ARMA) dapat dinyatakan sebagai $[6]$

$$
X_{t}=\theta_{0} Z_{t}+\alpha \sum_{k=1}^{t-1} \phi^{k-1} Z_{t-k}
$$

dengan $\alpha=\phi \theta_{0}-\theta$

Peta kendali ARMAST dibentuk berdasarkan data $X_{t}$ yang sudah stasioner, maka $E\left(X_{t}\right)=\mu_{X}=\mu$. Dari hasil penelitian diperoleh varians $X_{t}$ adalah

$$
\sigma_{X}^{2}=\left\{\theta_{0}^{2}+\frac{\alpha^{2}}{1-\phi^{2}}+2\left(\theta_{0} \alpha+\frac{\phi \alpha^{2}}{1-\phi^{2}}\right) \sum_{k=1}^{\infty} \phi^{k-1} \rho_{k}\right\} \sigma_{Z}^{2}
$$

Bentuk model ARMA $(1,1)$ untuk data menggunakan parameter $u$ dan $v$ dituliskan sebagai berikut

$$
Z_{t}=u_{1} Z_{t}+a_{t}-v_{1} a_{t-1} .
$$

Diperoleh varians $X_{t}$ untuk ARMA $(1,1)$

$$
\sigma_{X}^{2}=\left\{\theta_{0}^{2}+\frac{\alpha^{2}}{1-\phi^{2}}+2\left(\theta_{0} \alpha+\frac{\phi \alpha^{2}}{1-\phi^{2}}\right) \rho_{1}\left(\frac{1}{1-\phi u_{1}}\right)\right\} \sigma_{Z}^{2}
$$

sehingga batas-batas peta kendali ARMAST untuk ARMA(1,1) adalah

$$
\begin{aligned}
U C L & =\mu_{X}+L \sqrt{\left\{\theta_{0}^{2}+\frac{\alpha^{2}}{1-\phi^{2}}+2\left(\theta_{0} \alpha+\frac{\phi \alpha^{2}}{1-\phi^{2}}\right) \rho_{1}\left(\frac{1}{1-\phi u_{1}}\right)\right\} \sigma_{Z}^{2}} \\
C L & =\mu_{X} \\
L C L & =\mu_{X}-L \sqrt{\left\{\theta_{0}^{2}+\frac{\alpha^{2}}{1-\phi^{2}}+2\left(\theta_{0} \alpha+\frac{\phi \alpha^{2}}{1-\phi^{2}}\right) \rho_{1}\left(\frac{1}{1-\phi u_{1}}\right)\right\} \sigma_{Z}^{2}}
\end{aligned}
$$

\subsection{Peta Kendali ARMAST Data Pemakaian Gas PGN}

4.2.1. Pemodelan Data Pemakaian Gas PGN

\section{Identifikasi kestasioneran data}

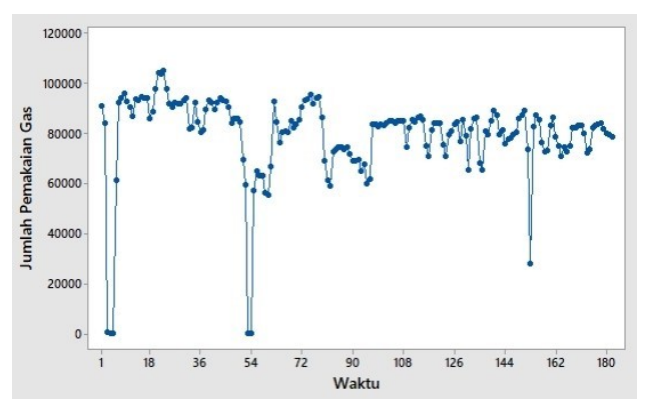

Gambar 2: Grafik data 
Berdasarkan Gambar 2 menunjukkan bahwa data gas PGN sudah stasioner terhadap nilai tengah dan varians karena titik-titik sampel data berada disekitaran rata-rata.

\section{Model data pemakaian gas PGN}

Plot ACF dan PACF menunjukan bahwa signifikan pada lag 1 dan 2, maka diperoleh bebearap dugaan model yaitu $\operatorname{ARMA}(1,1), \operatorname{ARMA}(1,2), \operatorname{ARMA}(2,1)$, dan $\operatorname{ARMA}(2,2)$.

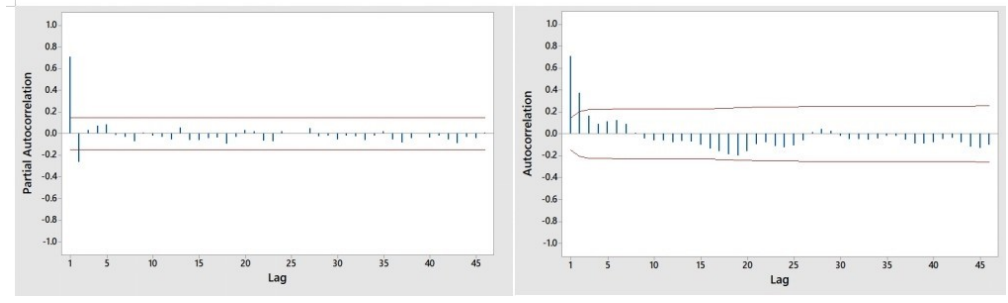

Gambar 3: Plot ACF dan PACF

Setelah diperoleh beberapa dugaan model, menentukan nilai parameter model dan AIC, lalu dilakukan pengujian signifikan parameter, serta uji LjungBox untuk memeriksa asumsi white noise pada masing-masing model.

Tabel 2: Kemungkinan model data gas PGN

\begin{tabular}{|c|c|c|c|c|c|}
\hline Model & \multicolumn{2}{|c|}{ Parameter } & Signifikansi & White Noise & AIC \\
\hline $\operatorname{ARMA}(1,1)$ & $\begin{array}{l}\phi_{1} \\
\theta_{1}\end{array}$ & $\begin{array}{l}0.564148 \\
0.318844\end{array}$ & $\sqrt{ }$ & $\sqrt{ }$ & 21.58798 \\
\hline $\operatorname{ARMA}(1,2)$ & $\begin{array}{l}\phi_{1} \\
\theta_{1} \\
\theta_{2}\end{array}$ & $\begin{array}{l}0.413434 \\
0.478160 \\
0.192558\end{array}$ & $\sqrt{ }$ & $\sqrt{ }$ & 21.58817 \\
\hline $\operatorname{ARMA}(2,1)$ & $\begin{array}{l}\phi_{1} \\
\phi_{2} \\
\theta_{1}\end{array}$ & $\begin{array}{c}0.895268 \\
-0.262528 \\
0.002440\end{array}$ & $\mathrm{X}$ & $\sqrt{ }$ & 21.59018 \\
\hline $\operatorname{ARMA}(2,2)$ & $\begin{array}{l}\phi_{1} \\
\phi_{2} \\
\theta_{1} \\
\theta_{2}\end{array}$ & $\begin{array}{c}0.656493 \\
-0.162515 \\
0.237271 \\
0.143862\end{array}$ & $\mathrm{X}$ & $\sqrt{ }$ & 21.59765 \\
\hline
\end{tabular}

Berdasarkan Tabel 2 diketahui bahwa model ARMA(1,1) memiliki parameter siginifikan, memenuhi asumsi white noise dan memiliki nilai AIC terkecil. Oleh karena itu, pembentukkan peta kendali ARMAST data gas PGN dilakukan menggunakan model $\operatorname{ARMA}(1,1)$.

\subsubsection{Peta Kendali ARMAST}

Peta kendali ARMAST untuk data gas PGN dengan model yang dipakai adalah ARMA(1,1). Data gas PGN memilliki nilai tengah $\mu=79389.0509$ dan variansi 
residual $\sigma_{a}=287614358.676$. Dengan menggunakan Persamaan (4.3), (4.4), dan (4.5) diperoleh $\mathrm{UCL}=120234.1354, \mathrm{CL}=79389.0509$, dan $\mathrm{LCL}=38543.966$.

Setelah diperoleh UCL, CL, dan CL selanjutnya dibentuk peta kendali ARMAST

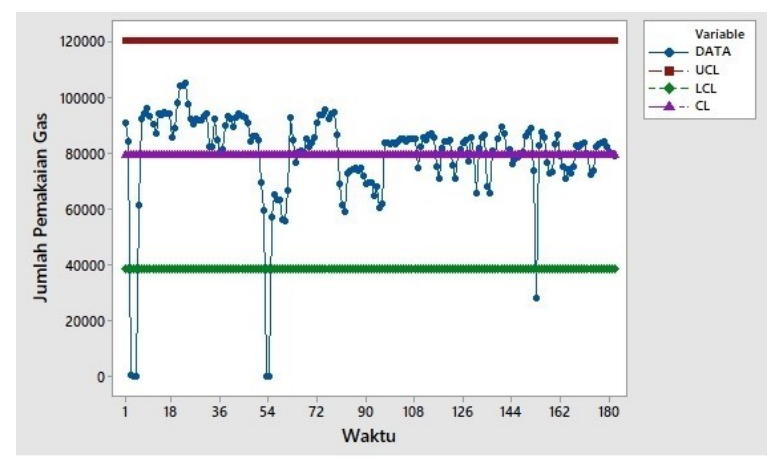

Gambar 4: Peta Kendali ARMAST

Gambar 4 menunjukkan bahwa terdapat data yang berada diluar batas kendali, hal tersebut berarti terdapat indikasi bahwa data pemakaian gas PGN oleh PT Indonesia Power pada periode Januari-Juni 2020 berada pada kondisi tidak terkendali secara statistik.

\section{Kesimpulan}

Berdasarkan hasil penelitian diambil kesimpulan bahwa peta kendali ARMAST untuk data pemakaian gas PGN di PT Indonesia Power UPJP Priok dibentuk berdasarkan model $\operatorname{ARMA}(1,1)$ yaitu

$$
\begin{gathered}
Z_{t}=\theta_{0} a_{t}-\theta_{1} a_{t-1}+\phi_{1} Z_{t-1} \\
Z_{t}=\theta_{0} a_{t}-0.318844 a_{t-1}+0.564148 Z_{t-1}
\end{gathered}
$$

dengan batas-batas peta kendali ARMAST adalah

$$
\begin{aligned}
U C L & =120234.1354 \\
C L & =79389.0509 \\
L C L & =38543.966
\end{aligned}
$$

Berdasarkan peta kendali yang terbentuk, disimpulkan bahwa pemakaian gas PGN di PT Indonesia Power pada periode bulan Januari-Juni 2020 berada pada kondisi tidak terkendali secara statistik dan tidak diketahui penyebab spesifik yang menjadi alasan data berada diluar batas kendali.

\section{Ucapan Terima kasih}

Penulis mengucapkan terima kasih kepada Ibu Izzati Rahmi HG, Ibu Des Welyyanti, dan Bapak Efendi yang telah memberikan masukan dan saran sehingga artikel ini 
498 Miftahul Jannah $R B d k k$

dapat diselesaikan dengan baik.

\section{Daftar Pustaka}

[1] Istikhomah. 2015. Aplikasi Peta Kendali P Sebagai Pengendalian Kualitas Karet di PTPN IX Batujamus/Kerjoarum. Jurnal Agraris. 1(1):12 - 23

[2] Montgomery, C. Douglas. 2009. Statistical Quality Control, 6th Edition. Asia : John Wiley and Sons (Asia) Pte. Ltd

[3] Montgomery, C. Douglas et.all. 2008. Introduction to Time Series Analysis and Forecasting. Canada : John Wiley and Sons, Inc

[4] Nelwati. 2015. Peta Kendali Exponentially Moving Average (EWMA) untuk Jumlah Wisatawan yang Berkunjung ke Sumatera Barat. Jurnal Matematika UNAND. 4(4): $83-90$

[5] Wei, William, W.S. 2006. Time series Analysis : Univariate and Multivariate Methods, 2nd Edition. USA: Pearson Educations, Inc

[6] W. Jiang, K.L. Tsui, and W.H. Woodall. 2000. A new SPC monitoring method: The ARMA chart. Technometrics. 42(4): 399 - 410 